\title{
ВРЕМЯ «В ДИАПАЗОНЕ» КАК ВАЖНЫЙ ПОКАЗАТЕЛЬ КОНТРОЛЯ У ДЕТЕЙ С САХАРНЫМ ДИАБЕТОМ 1 ТИПА ПРИ ПЕРЕВОДЕ НА АНАЛОГ ИНСУЛИНА СВЕРХДЛИТЕЛЬНОГО ДЕЙСТВИЯ ДЕГЛУДЕК
}

\author{
Гирш Я.В.
}

\author{
БУ ВО ХМАО-Югры «Сургутский государственный университет», Сургут
}

Использование современных инсулинов, индивидуальных глюкометров, средств самоконтроля, инсулиновых помп и средств непрерывного мониторирования гликемии определяет более строгие подходы к достижению компенсации углеводного обмена у пациентов с сахарным диабетом 1 типа.

Как оценить гликемический контроль? Какой параметр ведущий для оценки гликемического контроля? В настоящее время оценка уровня гликированного гемоглобина $\left(\mathrm{HbA}_{1 с}\right)$, гликемии натощак, постпрандиальной гликемии, эпизодов гипогликемии является недостаточным. Нам требуется максимально информативные параметры. Международный консенсус по использованию систем непрерывного мониторирования гликемии (НМГ), определил, что адекватная оценка гликемического контроля должна включать определение таких показателей, как время нахождения параметров в целевом диапазоне (Time In Range, TIR), в диапазоне ниже целевого (Time Below Range, TBR), в диапазоне выше целевого (Time Above Range, TAR) и применять коэффициент вариации гликемии (CV). TIR может быть использован не только в качестве конечной точки в клинических исследованиях, но и в качестве показателя гликемического контроля у пациентов с СД.

ЦЕЛЬ: дать оценку нахождения параметров в целевом диапазоне у детей с СД1 после смены базального инсулина детемир/гларгин 100 ЕД/мл на инсулин деглудек (IDeg).

МАТЕРИАЛЫ И МЕТОДЫ: представленный блок исследования проведен на базе БУ «Сургутская городская клиническая больница» с февраля по май 2021 года. Обследовано 18 детей с СД1 в возрасте $12,1 \pm 5,8$ [6,3; 17,9] лет. 12 мальчиков и 2 девочки. Длительность заболевания более 1 года: 5,1 33,1 [1,1; 8,2]. Исходный уровень $\mathrm{HbA}_{1 с}$ составил 8,2+1,3 [5,9; 9,5]. Оценивали: время нахождения параметров в целевом диапазоне, выше, ниже целевого по данным амбулаторного профиля глюкозы (АПГ) с использованием системы мониторирования гликемии с периодическим сканированием (ФМГ) до и после смены базального инсулина.

РЕЗУЛЬТАТЫ: все 18 пациентов завершили 1-й и 2-й (14-дневный) этапы ФМГ: 14-дневный мониторинг до перевода на базальный инсулин деглудек и 2-й 14-дневный мониторинг после перевода на базальный инсулин деглудек. В группе пациентов после перевода на IDeg отмечалось статистически значимое увеличение TIR $(54,1 \pm 8,8 \%$ до 69,3 $36,7 \%, p<0,01)$, уменьшение TBR $(10,3 \pm 3,1 \%$ до 3,4 $2,0 \%, p<0,01)$, уменьше-

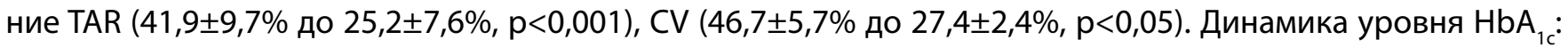
$8,2 \pm 1,3 \%-7,6 \pm 1,0 \%(p<0,05)$. У всех пациентов частота сканирований на 2-ом этапе увеличилась.

Перевод пациентов на IDeg осуществляется в отделении с февраля 2016 года. Инсулин деглудек обладает особыми характеристиками: стабильность, длительность гликемического действия, низкая вариабельность, возможность гибкого дозирования. Плоский стабильный эффект IDeg определяет потенциал для снижения риска гипогликемий у пациентов, в том числе, младшей возрастной группы. Не требуется увеличение частоты самоконтроля гликемии, что определяет возможность перевода на инсулин деглудек в амбулаторных условиях.

ВЫводы: при переводе на инсулин деглудек в 100\% случаев пациенты показали: увеличение \% времени нахождения в $\mathrm{TIR}$, уменьшение эпизодов и времени нахождения в условиях гипогликемии (TBR) и гипергликемии (TAR), снижение вариабельности гликемии. 